\title{
Estratégias para a melhoria da eficiência do cultivo folicular in vitro: Importância da suplementação do meio e estudo das alterações epigenéticas
}

\author{
Strategies for improving follicular culture efficiency in vitro: Importance of medium \\ supplementation and study of epigenetic changes \\ Estrategias para mejorar la eficiencia del cultivo folicular in vitro: Importancia de la \\ suplementación con medio y estudio de cambios epigenéticos
}

Recebido: 08/07/2021 | Revisado: 10/07/2021 | Aceito: 15/07/2021 | Publicado: 24/07/2021

\author{
Ana Flávia Bezerra da Silva \\ ORCID: https://orcid.org/0000-0002-0450-6039 \\ Universidade Estadual do Ceará, Brasil \\ E-mail: af.biomedica@gmail.com \\ Laritza Ferreira de Lima \\ ORCID: https://orcid.org/0000-0001-6391-7113 \\ Universidade Estadual do Ceará, Brasil \\ E-mail: laritza_lima@yahoo.com.br \\ José Ricardo de Figueiredo \\ ORCID: https://orcid.org/0000-0002-5139-0964 \\ Universidade Estadual do Ceará, Brasil \\ E-mail: jrf.lamofopapapers@gmail.com
}

\begin{abstract}
Resumo
Considerando o impacto que o estresse oxidativo (EO) e as alterações epigenéticas podem exercer sobre a foliculogênese, o melhor entendimento desses eventos nos auxiliam na busca da melhor eficiência do cultivo in vitro (CIV) de folículos ovarianos em diversas espécies. Diante disso, o objetivo dessa revisão é abordar as principais características e avanços do CIV folicular, expondo as suas limitações (ex. EO e alterações epigenéticas) e alternativas (ex. antioxidantes e meio condicionado de células-tronco mesenquimais - MC-CTMs). Para tanto, no presente artigo foi realizada uma revisão de literatura na qual foram empregadas um total de 143 referências bibliográficas, datadas de 1987 a 2021. Como critérios de inclusão, foram utilizados artigos experimentais, capítulos de livros e revisões de literatura na língua portuguesa, inglesa e espanhola. Em relação aos resultados e discussão, foi observado que os melhores resultados de CIV de folículos ovarianos pré-antrais foram obtidos em murinos com o nascimento de crias saudáveis. Atualmente os entraves dessa biotécnica têm sido correlacionados às condições inadequadas de cultivo, que causam aumento do EO e alterações nos padrões epigenéticos do folículo (oócitos e células somáticas). Dessa maneira, para transpor esse problema, vem-se testando a adição de diferentes substâncias ao meio de CIV, como antioxidantes, e meios oriundos do CIV de CTMs (ex. MC).
\end{abstract}

Palavras-chave: Alterações epigenéticas; Cultivo in vitro; Estresse oxidativo; Folículos ovarianos.

\begin{abstract}
The oxidative stress (OS) and epigenetic changes can impact folliculogenesis in different species. In vitro culture (IVC) of follicles efficiently will require a better understanding of these events. Therefore, the objective of this review is to address the main features and advances of IVC of ovarian follicles and exposing its limitations (i.e., OS and epigenetic changes) and alternatives (i.e., antioxidants and conditioned medium of mesenchymal stem cells - CMMSCs). In this review literature, 143 bibliographical references were used, dated from 1987 to 2021 . As inclusion criteria, experimental and review literature articles and chapters were used, published in Portuguese, English and Spanish. Various researches revealed that the best results obtained by IVC of preantral follicles in mice than other species with the birth of healthy offspring. Currently, inadequate in vitro culture conditions are a potent obstacle to this biotechnology has been reported. These conditions are responsible for increased OS and changes in the epigenetic patterns of follicles (oocytes and somatic cells). Thus, to overcome this problem, different substances added into the IVC medium, such as antioxidants and media from the IVC of MSCs (i.e., CM).
\end{abstract}

Keywords: Epigenetic changes; In vitro culture; Oxidative stress; Ovarian follicles.

\section{Resumen}

Considerando el impacto que el estrés oxidativo (EO) y los cambios epigenéticos pueden ejercer sobre la foliculogénesis, una mejor comprensión de estos eventos nos brindará mayor soporte para mejorar la eficiencia del cultivo in vitro (CIV) de folículos ováricos en diferentes especies. Por lo tanto, el objetivo de esta revisión es abordar 
las principales características y avances del CIV folicular, exponiendo sus limitaciones (p. ej. EO y cambios epigenéticos) y alternativas (p. ej. antioxidantes y medio condicionado de células madre mesenquimales - MCCMMs). Por consiguiente, en este artículo se realizó una búsqueda bibliográfica en la que se utilizaron un total de 143 referencias publicadas entre 1987 y 2021. Como criterios de inclusión, se utilizaron artículos experimentales, capítulos de libros y revisiones bibliográficas en portugués, inglés y español. En cuanto a los resultados y discusión, se observó que los mejores resultados de CIV fueron utilizando folículos preantrales de ratones, alcanzando el nacimiento de descendencia sana. Actualmente, las barreras de esta biotecnología se han correlacionado con unas condiciones de cultivo inadecuadas, que provocan un aumento del EO y alteraciones en los patrones epigenéticos del folículo (ovocitos y células somáticas). Así, para superar este problema, se ha probado la adición de diferentes sustancias al medio CIV, como antioxidantes, y medios obtenidos del CIV de CMMs (p. ej. MC).

Palabras clave: Cambios epigenéticos; Cultivo in vitro; Estrés oxidativo; Folículos ováricos.

\section{Introdução}

O cultivo in vitro (CIV) folicular permite recuperar os folículos ovarianos pré antrais (FOPAs) e antrais (FOAs) antes que se tornem atrésicos, cultivá-los até sua completa maturação, para obter um grande número de oócitos competentes que poderão ser utilizados na produção in vitro de embriões (PIVE; Figueiredo, Cadenas, Lima, \& Santos, 2019). O progresso mais relevante do CIV de FOPAs e FOAs foi relatado nas espécies murinas e bovinas, com a produção de crias vivas a partir do CIV de folículos primordiais e terciários, respectivamente (Eppig \& O’brien, 1996; Yamamoto et al., 1999). A dificuldade em se reproduzir bons resultados estão correlacionados a vários fatores, incluindo o estresse oxidativo (EO), ocasionado pela grande quantidade de espécies reativas de oxigênio (EROs) nas condições in vitro. O EO pode causar danos aos componentes celulares (organelas e DNA), além de anormalidades no perfil de metilação (PM; Saeedabadi, Abazari-kia, Rajabi, Parivar, \& Salehi, 2018).

O PM envolve a adição do radical metil $\left(\mathrm{CH}_{3}\right)$ nos resíduos de lisina $(\mathrm{K})$ das histonas, que pode normalmente ativar ou silenciar a expressão gênica durante os processos de oogênese, foliculogênese e embriogênese (Seneda, Godmann, Murphy, Kimmins, \& Bordignon, 2008; Souza-Cáceres \& Melo-Sterza, 2017). Trimetilação de H3K4me3 está associada com a ativação, enquanto a H3K9me3 está associada com o silenciamento da expressão gênica, o que tem um papel crítico na regulação de diversos processos reprodutivos (Yu et al., 2018). O nível de metilação nos resíduos K é dinamicamente regulado por enzimas lisinas metiltransferases (KTMs) que transferem o $\mathrm{CH}_{3}$ e lisinas demetilases (KDMs) que removem o $\mathrm{CH}_{3}$. Dentre as KDMs, destacam-se a KDM1A de H3K4me3 e KDM3A de H3K9me3 (Glanzner et al., 2018). Diversos autores têm observado que o EO no CIV ocasiona um desbalanço no PM, afetando principalmente a expressão de genes que codificam fatores parácrinos e enzimas cruciais para a regulação gênica (Yu et al., 2018; Sha et al., 2020).

Diante disso, a utilização de substâncias com capacidade antioxidante no meio de CIV pode melhorar a sobrevivência e desenvolvimento celular, por reduzir os danos causados pelo EO. Dentre essas substâncias pode-se destacar, o antioxidante anetol e o meio condicionado (MC) obtido de células-tronco mesenquimais (CTMs), os quais reduziram níveis de EROs ao serem adicionados no meio de CIV de FOPAs e FOAs (caprinos; Sá et al., 2017; Sá et al., 2018; Sá et al., 2020) e FOPAs (ovinos; Bezerra et al., 2019). Portanto, o objetivo dessa revisão é abordar as principais características e avanços do CIV folicular, expondo as suas limitações (ex. EO e alterações epigenéticas) e alternativas (ex. antioxidantes e MC-CTMs).

\section{Metodologia}

Para alcançar o objetivo, foi proposta uma revisão de literatura. Esse tipo de revisão é conceituado como uma análise meticulosa e ampla de publicações correntes em uma estabelecida área do conhecimento. As pesquisas de revisão de literatura são aquelas que se apoiam de publicações científicas em periódicos, livros etc. não se dedicando à coleta de dados in natura, porém não se restringindo somente a uma simples transcrição de ideias (Brasileiro, 2013).

Diante disso, a fundamentação teórica dessa revisão compreende um total de 143 referências bibliográficas, datadas 
de 1987 a 2021. Essas referências foram pesquisadas nas bases de dados: Scielo, Science direct e Pubmed, por meio das seguintes palavras-chave: Epigenetic changes; In vitro culture; Oxidative stress e Ovarian follicles. Como critérios de inclusão, foram utilizados artigos experimentais, capítulos de livros e revisões de literatura na língua portuguesa, inglesa e espanhola. Já como critérios de exclusão, foram desconsiderados formatos de textos que não tiveram avaliação rigorosa.

\section{Resultados e Discussão}

\subsection{Aspectos Gerais da Oogênese e Foliculogênese In Vivo}

O ovário mamífero é um órgão do sistema reprodutor feminino, responsável pela liberação de um oócito maturo, para ser fecundado e propagar espécies (Mcgee \& Hsueh, 2000), bem como pela síntese de hormônios e fatores de crescimento que regulam a fisiologia reprodutiva (Edson, Nagaraja, \& Matzuk, 2009). No tocante a sua estrutura, o ovário é constituído por duas diferentes regiões: medular, responsável pela sustentação do órgão, e cortical, a qual é preenchida por células estromais (intersticiais), corpos lúteos e folículos ovarianos em vários estádios de desenvolvimento (Richards \& Pangas, 2016).

Durante a vida fetal, o ovário primitivo é colonizado por células germinativas primordiais (CGPs; diploides ou 2n), que migraram a partir do saco vitelínico. Após a colonização, as CGPs diferenciam-se em oogônias (2n) que sofrem sucessivas divisões mitóticas e, posteriormente ingressam na primeira divisão meiótica e originam o oócito primário ou imaturo (célula haploide - n; Mclaughlin \& Mciver, 2009). Porém, neste momento a divisão celular é interrompida no diplóteno da prófase I (PI; $1^{a}$ parada da meiose), permanecendo o oócito primário neste estádio pelo menos até a puberdade. Além dos eventos meióticos descritos, os oócitos primários que estão em PI, começam a ser circundados por camadas de células da pré-granulosa de formato pavimentoso, caracterizando assim, o folículo primordial e dando início, então, ao processo de foliculogênese (Mcnatty et al., 2000; Mclaughlin \& Mciver, 2009).

A foliculogênese é denominada como o processo de formação, ativação, crescimento e maturação dos folículos (Juengel et al., 2002; Van Den Hurk \& Zhao, 2005). Além disso, a foliculogênese é dividida em duas fases: Fase pré-antral que compreende o desenvolvimento de FOPAs (primordial, transição, primário e secundário) e Fase antral que envolve a progressão de FOAs terciários ao estádio pré-ovulatório (Figura 1; Figueiredo \& Lima, 2017). Os FOPAs caracterizados pela (ausência da cavidade antral) e FOAs pela (presença da cavidade antral) representam 90\% e 10\% da população folicular ovariana, respectivamente. 
Figura 1 - Processo de foliculogênese: Fase pré-antral, ativação e crescimento folicular (1) e (2): (a) Ativação do folículo primordial (saída do pool de reserva quiescente) para o pool de folículos em desenvolvimento (b, c, d) com a multiplicação das células da granulosa (CG) e teca, caracterizando o crescimento folicular. Fase antral, crescimento e maturação folicular (3): (e) Folículo terciário com oócito imaturo circundado por diversas camadas de CG de formato cuboide, formação da cavidade antral repleta de fluido (constituído por carboidratos, aminoácidos, fatores de crescimento, hormônios e outras substâncias), maturação de células da teca que se tornam esteroidogênicas sob influência de hormônio luteinizante (LH). Assim, sob o controle de hormônio folículo estimulante (FSH), o folículo terciário continua crescendo até se tornar o folículo dominante, que em seguida, se tornará o pré-ovulatório com a expansão da cavidade antral (f). Após o pico de LH, o oócito retoma a meiose (núcleo em PI $\rightarrow$ metáfase II - MII e extrusão do $1^{\circ}$ corpúsculo polar) no folículo pré-ovulatório e ocorre a ovulação de um oócito maturo (g) em espécies monovulatórias.

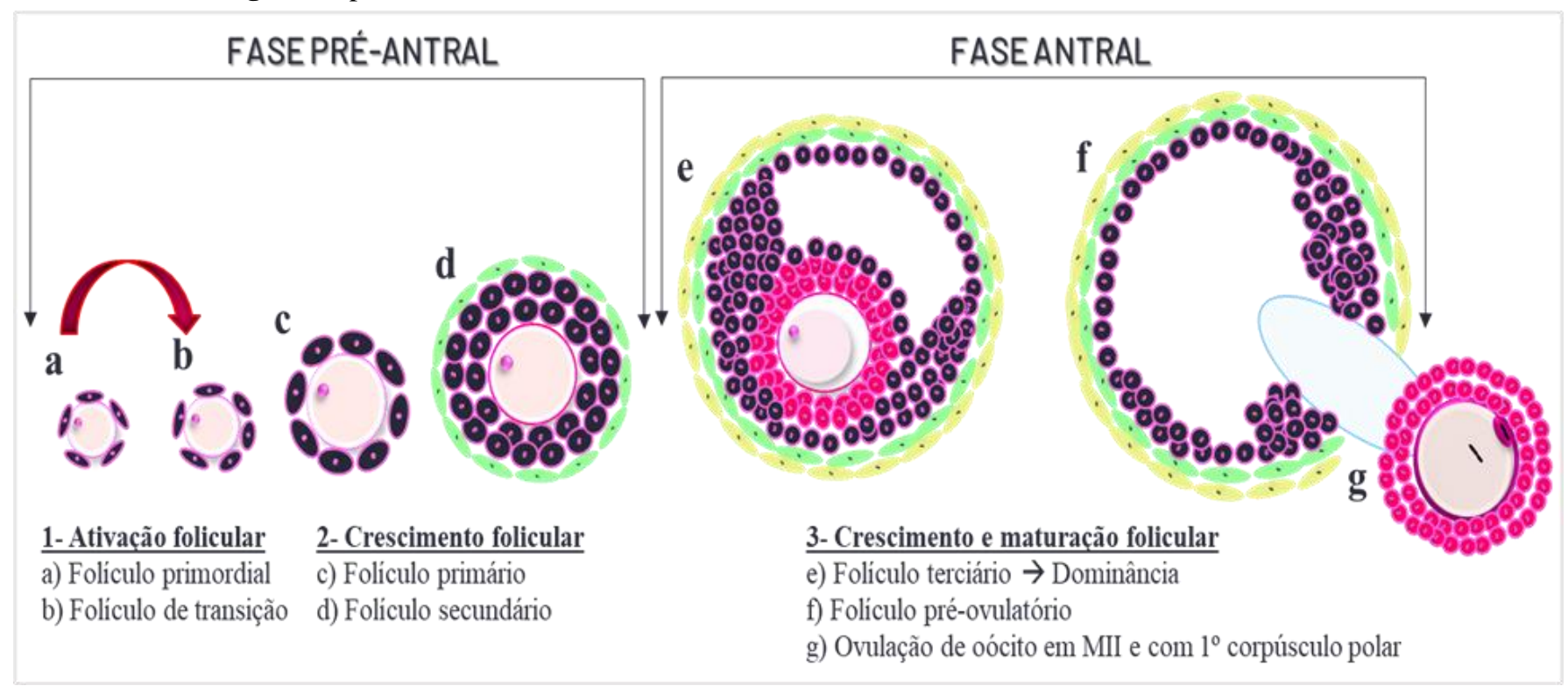

Fonte: Adaptado de Sales et al., (2015); Spitschack; Hoeflich, (2018); Figueiredo et al., (2019).

Conforme mencionado em espécies monovulatórias, apenas um folículo passará pelo processo de ovulação, posterior ao pico de LH (Fortune, Rivera, Evans, \& Turzillo, 2001). Portanto somente uma pequena parte dos FOPAs ativados se desenvolverão até a ovulação, pois a maioria morrerá por atresia (Figueiredo, Rodrigues, Amorim, \& Silva, 2008). A atresia folicular é um evento natural regulado por um balanço entre fatores anti e pró-apotóticos, e que afeta majoritariamente a apoptose das CG (Kaipia \& Hsueh, 1997; Manabe et al., 2004). Na literatura é relatado inúmeras substâncias anti-apoptóticas, como hormônios FSH e estradiol, e fatores de crescimento (Rodrigues Limback, Mcginnis, Plancha, \& Albertini, 2008). Já em relação às pró-apoptóticas, destacam-se diversos ligantes de receptores de morte envolvidos nesse evento, como TNF- $\alpha$, ligante Fas, ligante indutor de apoptose relacionado a TNF (TRAIL), ligante APO-3 e ligante PFG-5 (Kaipia \& Hsueh, 1997; Matsuda et al., 2008; Zhou, Peng, \& Mei, 2019).

Tendo em vista que a maioria dos folículos será eliminada por atresia, o CIV folicular vem sendo desenvolvido com o objetivo de recuperar esses folículos antes que se tornem atrésicos e cultivá-los até sua completa maturação, a fim de conseguir um grande número de oócitos competentes que poderão ser utilizados por outras biotécnicas, como a PIVE (Figueiredo, Cadenas, Lima, \& Santos, 2019).

\subsection{Cultivo In Vitro de Folículos Ovarianos}

Existem dois tipos de sistemas para se cultivar folículos: cultivo "in situ", no qual os folículos são cultivados inclusos em fragmentos do córtex ovariano ou do ovário inteiro, e o cultivo de folículos “isolados” do córtex (O’brien, Pendola, \& Eppig, 2003). O CIV de folículos isolados mecanicamente com agulhas (Telfer, 1998) é a forma mais utilizada por permitir o acompanhamento individualizado dos folículos, além de maximizar o seu respectivo contato com o meio de CIV (Abir, Nitke, Ben-Haroush, \& Fisch, 2006). Folículos isolados têm sido cultivados de duas formas, bidimensional (2D), em que os folículos 
são diretamente cultivados sobre a placa de cultivo ou tridimensional (3D), em que os folículos são cultivados em uma matriz extracelular, como o alginato (Panta et al., 2019).

Os resultados mais promissores do CIV de FOPAs incluem o nascimento de crias vivas após CIV de folículos primordiais murinos (Eppig \& O’brien, 1996; O’brien, Pendola, \& Eppig, 2003; Morohaku et al., 2016), utilizando um cultivo de dois passos, ou seja, iniciando com cultivo in situ e finalizando com cultivo do foliculo isolado. Mas, apesar desses resultados, várias pesquisas ainda precisam ser realizadas para alavancar o sucesso de CIV de FOPAs nas diversas espécies de mamíferos, pois as taxas de oócitos em MII e de embriões produzidos (Arunakumari, Shanmugasundaram, \& Rao, 2010; Magalhães et al., 2011) ainda são extremamente baixas. Em contrapartida, o CIV de FOAs já alcançou uma representativa taxa de oócitos em MII (Ref. 57,7\%) e prenhez (Sá et al., 2020) em caprinos. Além disso, em bovinos, esse tipo de CIV obteve consideráveis taxas de blastocistos (Ref. 43,2\%; Huang, Nagano, Kang, Yanagawa, \& Takahashi, 2013) e nascimento de uma cria viva (Yamamoto et al., 1999). Dessa maneira, esses achados mostram que FOPAs e FOAs requerem meios específicos para sua sobreviência e posterior desenvolvimento.

De fato, Magalhães-Padilha et al. (2013) identificaram que aproximadamente 2.466 genes foram expressos de forma específica em (FOPAs ou FOAs), após análise de microarray. Indicando que esses folículos apresentam diferentes padrões de expressão gênica e, consequentemente, requerimentos em relação ao CIV folicular. Desse modo, a complexidade de regulação da foliculogênese e diferentes requerimentos entre as categorias podem afetar a eficiência do CIV. Sendo assim, o conhecimento dos fatores limitantes que afetam essas vias são de suma importância. Dentre os fatores limitantes, destacam-se: Estresse oxidativo (EO); Alterações epigenéticas; Meios e suplementos que serão descritos a seguir.

\subsection{Fatores que Afetam a Eficiencia do Cultivo In Vitro de Folículos Ovarianos}

\subsubsection{Estresse Oxidativo}

O EO é desencadeado por um desequilíbrio entre a formação de EROs e os níveis de antioxidantes que fazem parte do sistema de defesa das células. Vale salientar que a formação de EROs como: o peróxido de hidrogênio $\left(\mathrm{H}_{2} \mathrm{O}_{2}\right)$, o ânion superóxido $\left(\mathrm{O}_{2}-\right)$ e o radical hidroxila $(\mathrm{OH}-)$ pode ocorrer de forma endógena ou exógena (Covarrubias et al., 2008; Schafer \& Buettner, 2001; Qingming et al., 2010; Silva, Araújo, Duarte, \& Lopes, 2011a; Sahebkar, Serban, Ursoniu, \& Banach, 2015).

As EROs endógenas são normalmente provenientes do metabolismo oxidativo celular, incluindo o metabolismo de células envolvidas nos processos fisiológicos reprodutivos, como esteroidogênese folicular e luteal, maturação oocitária, ovulação e fecundação (Agarwal \& Allamaneni, 2004; Fujii, Iuchi, \& Okada, 2005; Hammadeh et al., 2008). No ovário, as EROs endógenas são produzidas dentro do microambiente folicular, controlando a função ovariana por meio de vias de sinalização intracelulares (Devine, Pereeault, \& Luderer, 2012). Já às EROs exógenas são produzidas em excesso pelo metabolismo oxidativo celular, devido principalmente às condições inadequadas de $\mathrm{CIV}$, como: altas tensões de oxigênio $\left(\mathrm{O}_{2}\right)$; exposição à luz e meios de CIV contendo concentrações elevadas de substâncias como metais (Ferro e cobre) e fluídos biológicos (SFB e BSA; Torres-Osorio, Urrego, Echeverri-Zuluaga, \& López-Herrera) resultando assim no EO.

O EO é responsável por alterar diversas moléculas intracelulares e causar prejuízos dentre os quais podemos citar os danos nos componentes celulares (DNA e organelas; Vaanholt et al., 2015). In vivo, altas concentrações de EROs exógenas podem comprometer a capacidade do oócito de ser fecundado pelo espermatozoide (Hammadeh et al., 2008). In vitro, estudos mostraram que altas concentrações de EROs exógenas podem prejudicar a sobrevivência, desenvolvimento folicular e afetar negativamente a competência de oócitos ao desenvolvimento embrionário (Sá et al., 2018; Sá et al., 2020); produzir gametas defeituosos (Du Plessis, Makker, Desai, \& Agarwal, 2008); além de aumentar as alterações epigenéticas em oócitos e blastocistos (Bomfim et al., 2017; Liu et al., 2020). 


\subsubsection{Alterações Epigenéticas}

Diversas biotecnologias reprodutivas como maturação (Saeedabadi, Abazari-kia, Rajabi, Parivar, \& Salehi, 2018; Bennemann, Grothmann, \& Wrenzycki, 2018), fecundação (Wrenzycki \& Niemann, 2003; Glanzner et al., 2018) e CIV de embriões (Bomfim et al., 2017) podem ocasionar alterações epigenéticas durante as fases de desenvolvimento oocitário e embrionário. Por esse motivo, sugere-se que o mesmo pode ocorrer na biotécnica de CIV, já que essas alterações epigenéticas podem ser influenciadas pelas condições ambientais (Metere \& Graves, 2020).

As mutações epigenéticas são conceituadas como alterações químicas na função gênica e que não envolvem mudanças nas sequências do DNA (Silva \& Jasiulionis, 2014). Diversos mecanismos epigenéticos podem moldar a cromatina e principalmente a função gênica (Souza \& Melo, 2017). Dentre os inúmeros mecanismos epigenéticos, destacam-se a metilação do DNA (5-metilcitosina), modificações covalentes das histonas e expressão de vários microRNAs não codificantes (Liu, Zhang, Wu, Dai, \& Koji, 2018). O foco da presente revisão foi reportar a mudança do nível de metilação do DNA ocasionada pelas modificações covalentes das histonas.

Histonas são carregadas positivamente na região amino terminal (cauda) com resíduos abundantes de lisina (K), portanto, pode se fixar firmemente ao DNA para restringir sua acessibilidade. Cada nucleossomo contém um octâmero de histona que consiste em dois de cada monômero de histona (H2A, H2B, H3 e H4). Aproximadamente 80\% do DNA genômico é empacotado em nucleossomos e os $20 \%$ restantes estão contidos na região ligante que conecta nucleossomos vizinhos (Chen, Li, Subramaniam, \& Shyy, 2017).

Modificações covalentes das histonas, como a metilação (adição do radical metil - $\mathrm{CH}_{3}$ aos resíduos de $\mathrm{K}$ ), podem desencadear a ativação ou silenciamento dos genes adjacentes por meio do recrutamento de mecanismos regulatórios, como complexos de remodelação da cromatina, fatores de transcrição, bem como coativadores e cossupressores transcricionais. Especialmente a H3K4me1 (metil-histona H3; K-4); H3K4me3 (trimetil-histona H3; K-4) e H3K36me3 (trimetil-histona H3; K-36) estão relacionadas com a ativação e em contrapartida, a H3K9me3 (trimetil-histona H3; K-9) e H3K27me3 (trimetilhistona H3; K-27) estão relacionadas com o silenciamento da expressão gênica (Pasini et al., 2008). Já a H3K4me2 (dimetilhistona H3; K4) está ligada a ativação ou silenciamento da expressão gênica (LIU et al., 2020).

Além disso, o nível de metilação nos resíduos de (K) é controlado pela ação de enzimas catalisadoras como as lisinas metiltransferases (KTMs; escritoras) que transferem o $\mathrm{CH}_{3}$ e lisinas demetilases (KDMs; apagadoras) que removem o $\mathrm{CH}_{3}$ (Pflum, Tong, Lane, \& Schreiber, 2001; Hiyun, Jeon, Park, \& Kim, 2017; Nacev et al., 2019). Dentre as KDMs, destacam-se as KDMs (1A, 5A e 5B) de H3K4 (Huang et al., 2015; Liu et al., 2016; Dahl et al., 2016; Glanzner et al., 2017); KDMs (2A, 2B, 4A, 4B, 4D) de H3K36 (Tsukada et al., 2006; Cloos et al., 2006; Klose et al., 2006); KDMs (3A, 3B, 3C, 4A, 4B e 4C) de H3K9 (Glanzner et al., 2018) e KDMs (6A, 6B e 7A) de H3K27 (Huang et al., 2015; Glanzner et al., 2018; Figura 2). 
Figura 2 - A cromatina é composta de nucleossomos. Cada nucleossomo é composto de 140pb de DNA enrolado em um octâmero de histona que contêm dois de cada monômero de histona (H2A; H2B; H3 e H4). Os resíduos localizados nas caudas amino terminais das histonas estão sujeitos a múltiplas modificações pós-tradução, incluindo a metilação, caracterizada pela adição do radical metil $\left(\mathrm{CH}_{3}\right)$. A adição do $\mathrm{CH}_{3}$ pode ocorrer em 4 principais resíduos $(\mathrm{K})$ das $\mathrm{H} 3$. A adição do $\mathrm{CH}_{3}$ nesses resíduos foi ligada à ativação (H3K4 e H3K36) e silenciamento (H3K9 e H3K27) da expressão gênica. Vale mencionar que a regulação da metilação, bem como a remoção do $\mathrm{CH}_{3}$ nesses resíduos (H3K4; H3K36; H3K9 e H3K27) são realizadas por meio de diferentes KDMs conforme ilustrado na figura.

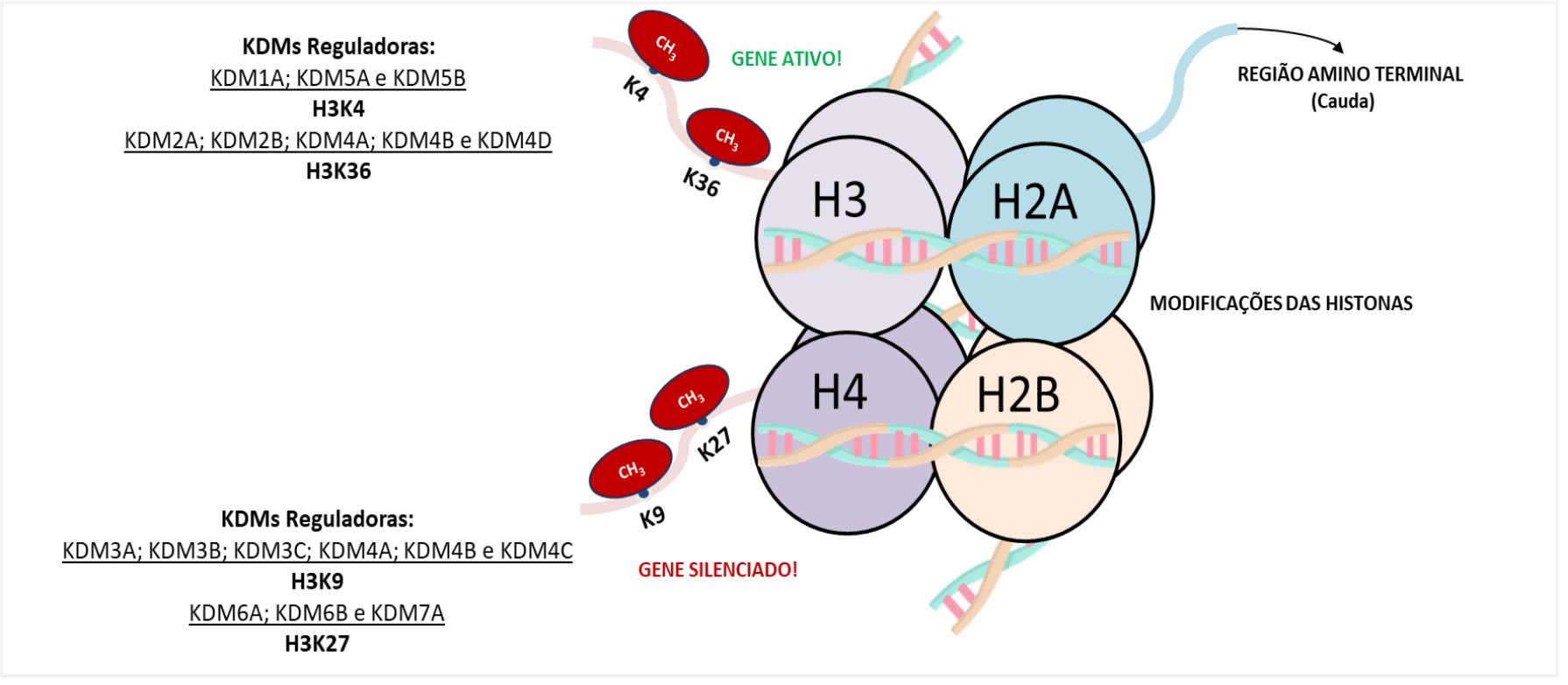

Fonte: Autores.

Atualmente sabe-se que os processos de oogênese e foliculogênese são normalmente regulados pela metilação nos resíduos K das histonas. Essa importância é representada pelo comportamento dinâmico da transcrição gênica nesses diferentes processos, os quais exigem uma modulação da cromatina. Por outro lado, como mencionado anteriormente, sabe-se também que a metilação nesses resíduos pode ser desregulada em condições de CIV, e por esse motivo, pesquisas vêm sendo desenvolvidas in vivo com o objetivo de entender como a desregulação da metilação pode afetar a sobrevivência e desenvolvimento (folicular e oocitário), sobre a possibilidade de manipular tal desregulação e melhorar a eficiência do CIV (Figura 3). 
Figura 3 - Esquema ilustrativo dos estudos de investigação das modificações covalentes das histonas in vivo e in vitro. Em tecido ovariano de suínos e murinos, a H3K4me3 foi detectada em folículos pré-antrais (FOPAs) e antrais (FOAs). Enquanto em babuínos, a H3K9me3 foi detectada apenas em FOPAs. Já em suínos, a H3K9me3 foi significativamente aumentada após a maturação in vitro (MIV) de oócitos recuperados de FOAs. Além disso, foi visto que em suínos e caprinos, quando o ácido ascórbico e um inibidor da KDM1A foram adicionados ao meio de MIV, aumentaram significativamente as H3K4me3 e H3K36me3, e H3K4me2, respectivamente. Principalmente nesse último estudo, o resultado ( $\uparrow$ H3K4me2) foi seguido de diversas anormalidades como: aumento da expressão de genes apoptóticos, danos nos fusos, cromossomos e organização da actina.

\section{Tecido ovariano - IN VIVO}

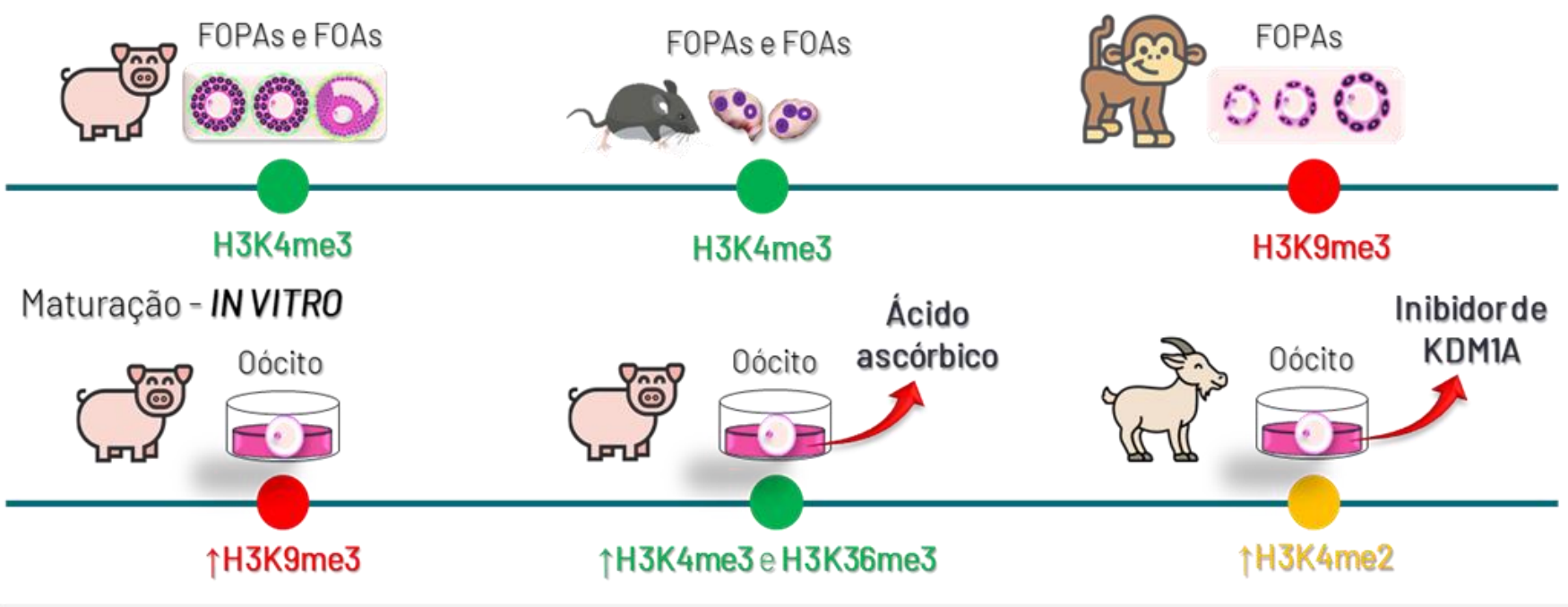

Fonte: Adaptado de Seneda, Godmann, Murphy, Kimmins, e Bordignon, (2008); Baumann, Olso, Wang, Fazleabas, e De La Fuente, (2015); Bunkar, Pathak, Lohiya, e Mishra, (2016); Yu et al., (2018); Liu et al., (2020); Sha et al., (2020).

Portanto, esses estudos demonstram que as condições in vitro (como a composição do meio) ocasiona alterações epigenéticas anormais no oócito. Uma alternativa para reduzir esses efeitos, é a utilização de meios e suplementos em concentrações adequadas.

\subsubsection{Meios e Suplementos}

O CIV utiliza meios de base extremamente ricos em nutrientes, eletrólitos, antioxidantes, aminoácidos, substratos energéticos, vitaminas, tampões, hormônios e/ou fatores de crescimento (Picton, Harris, Muruvi, \& Chambers, 2008; Figueiredo, Rodrigues, Amorim, \& Silva, 2008). Meios de base comerciais como o Meio Essencial Mínimo-alfa modificado ( $\alpha$-MEM), Meio de Cultivo de Tecido 199 (TCM 199) e McCoy’s têm sido utilizados no CIV em diferentes espécies (Arunakumari, Shanmugasundaram, \& Rao, 2010; Mclaughlin \& Telfer, 2010; Leitão et al., 2014).

Apesar do $\alpha$-MEM ser um meio rico em aminoácidos, vitaminas, sais inorgânicos, compostos energéticos, ribonucleosídeos e desoxirribonucleosídeos, outras substâncias têm sido adicionadas a ele, tais como o selênio (Abedelahi, Salehnia, \& Allameh, 2010), o ácido ascórbico (Andrade et al., 2012) e a transferrina (Durlej, Duda, Knapcyk, \& Słomczyńska, 2008), compostos energéticos como a glutamina, o piruvato e a hipoxantina, porque esses compostos auxiliam na manutenção da sobrevivência e ultraestrutura dos folículos (Figueiredo et al., 1994). Vale destacar que a hipoxantina adicionada no meio de CIV, promoveu uma maior interação entre o oócito e as CG (Eppig \& Downs, 1987).

A proteína albumina sérica bovina (BSA) é muito utilizada no meio de CIV por favorecer o desenvolvimento folicular e a produção de oócitos meioticamente competentes (Rodrigues et al., 2010), bem como manter a estrutura tridimensional folicular (Itoh, Kacchi, Abe, Sendai, \& Hoshi, 2002). Há ainda outras substâncias, como hormônios: insulina, FSH, hormônio do crescimento (GH) e tiroxina (Ferreira et al., 2016; Cadenas et al., 2017; Ferreira et al., 2020; Paes et al., 2020), fatores de 
crescimento: fator semelhante à insulina tipo 1 (IGF-1), fator de crescimento epidérmico (EGF), fator fibroblástico básico (FGF-2) e fator endotelial vascular (VEGF; Costa et al, 2014; Santos et al., 2014a; Santos et al, 2014b; Cadenas et al., 2017), MC produzido a partir de CTMs (Bezerra et al., 2019) e antioxidantes, como anetol (Sá et al., 2020) que também ao serem adicionados ao meio estimulam e favorecem o desenvolvimento dos folículos cultivados in vitro.

\subsubsection{Antioxidantes}

A síntese e o desbalanço de EROs exógenas podem ser controlados por meio da utilização de antioxidantes no meio de CIV, que mesmo em pequenas concentrações possuem a função de inibir ou atrasar a oxidação de um substrato (Idelchik, Begley, Begley, \& Melendez, 2017). O sistema de defesa antioxidante pode ser classificado como enzimático e não enzimático (Okediran, Biobaku, Olaifa, \& Atata, 2017). O sistema de defesa antioxidante enzimático inclui as enzimas superóxido dismutase (SOD), glutationa peroxidase (GPx) e a catalase (CAT; Laguerre, Lecomte, \& Villeneuve, 2007). A enzima SOD age transformando dois $\mathrm{O}_{2}$ em $\mathrm{O}_{2}$ e $\mathrm{H}_{2} \mathrm{O}_{2}$. Já a CAT e a GPx agem de forma simultânea com a glutationa reduzida (GSH) para transformar o $\mathrm{H}_{2} \mathrm{O}_{2}$ em água $\left(\mathrm{H}_{2} \mathrm{O}\right.$; Young \& Woodside, 2001). Em contrapartida, os antioxidantes não enzimáticos são compostos que podem ser obtidos a partir de nutrientes exógenos, tais como os elementos naturais ou suplementos alimentares (Fang, Yang, \& Wu, 2002), como os fenilpropanoides e flavonoides (Amarowicz, Pegg, Rahimi-Moghaddam, Barl, \& Weil, 2004) que incluem os antioxidantes anetol, eugenol, resveratrol, dentre outros que estão listados nos Quadros 1 e 2. 
Research, Society and Development, v. 10, n. 9, e22910918022, 2021

(CC BY 4.0) | ISSN 2525-3409 | DOI: http://dx.doi.org/10.33448/rsd-v10i9.18022

Quadro 1 - Impacto da suplementação de agentes antioxidantes durante o cultivo de folículos pré-antrais inclusos no tecido ovariano de ruminantes.

\begin{tabular}{|c|c|c|c|c|c|c|c|}
\hline Antioxidantes & $\begin{array}{c}\text { Melhores } \\
\text { concentrações }\end{array}$ & Espécies & $\begin{array}{l}\text { Duração do } \\
\text { cultivo } \\
\text { (horas/dias) }\end{array}$ & $\begin{array}{c}\text { Ativação folicular } \\
\text { (primordial para estádios de } \\
\text { transição ou primário) }\end{array}$ & $\begin{array}{l}\uparrow \text { Diâmetro } \\
\text { folicular e/ou } \\
\text { oocitário }\end{array}$ & $\begin{array}{l}\downarrow \text { de EROs e/ou } \\
\uparrow \text { capacidade } \\
\text { antioxidante }\end{array}$ & Autores \\
\hline \multirow{2}{*}{ Anetol } & $30 \mu \mathrm{g} / \mathrm{mL}$ & Caprina & 7 dias & Sim & $\operatorname{Sim}$ & Sim & Sá et al. (2018) \\
\hline & $2000 \mu \mathrm{g} / \mathrm{mL}$ & Ovina & 24 horas & Sim & NA & Sim & Morais (2018) \\
\hline Ácido ascórbico & $50 \mu \mathrm{g} / \mathrm{mL}$ & Caprina & 14 dias & Sim & Sim & NA & Rossetto et al. (2009) \\
\hline$\alpha$-Tacoferol & $5 \mu \mathrm{M}$ & Caprina & 5 dias & Sim & Não & NA & Lima-Verde et al. (2009) \\
\hline \multirow{2}{*}{ Melatonina } & \multirow{2}{*}{$1000 \mathrm{pM}$} & Caprina & 7 dias & Não & Sim & NA & Rocha et al. (2013) \\
\hline & & Bovina & 6 dias & Sim & Sim & NA & Cavalcante et al. (2019) \\
\hline Robinina & 0,125 mg/mL & Ovina & 24 horas & Sim & NA & Sim & Morais (2018) \\
\hline
\end{tabular}

Nota: NA: Não avaliado. $\uparrow$ : Aumentou. $\downarrow$ : Diminuiu. Fonte: Autores. 
Research, Society and Development, v. 10, n. 9, e22910918022, 2021

(CC BY 4.0) | ISSN 2525-3409 | DOI: http://dx.doi.org/10.33448/rsd-v10i9.18022

Quadro 2 - Impacto da suplementação de agentes antioxidantes durante o cultivo de folículos pré-antrais e antrais isolados do córtex ovariano de ruminantes.

\begin{tabular}{|c|c|c|c|c|c|c|c|c|}
\hline Antioxidantes & $\begin{array}{c}\text { Melhores } \\
\text { concentrações }\end{array}$ & Espécies & $\begin{array}{l}\text { Folículos } \\
\text { cultivados }\end{array}$ & $\begin{array}{c}\text { Duração de } \\
\text { cultivo } \\
\text { (dias) }\end{array}$ & $\begin{array}{l}\uparrow \text { Diâmetro folicular } \\
\text { e/ou oocitário }\end{array}$ & $\begin{array}{l}\text { Formação de } \\
\text { antro }\end{array}$ & $\begin{array}{c}\downarrow \text { de EROs e/ou } \uparrow \\
\text { capacidade } \\
\text { antioxidante }\end{array}$ & Autores \\
\hline \multirow{2}{*}{ Anetol } & \multirow{2}{*}{$300 \mu \mathrm{g} / \mathrm{mL}$} & \multirow{2}{*}{ Caprina } & FOPAs & \multirow{2}{*}{18} & Não & Sim & Sim & Sá et al. (2017) \\
\hline & & & FOAs & & Sim & NA & $\operatorname{Sim}$ & Sá et al. (2020) \\
\hline Astaxantina & $10 \mu \mathrm{g} / \mathrm{mL}$ & Bovina & FOAs & 12 & Não & NA & Sim & Chelenga et al. (2020) \\
\hline Ácido ascórbico & $50 \mu \mathrm{g} / \mathrm{mL}$ & Caprina & FOPAs & 18 & Sim & Sim & NA & Silva et al. (2011b) \\
\hline Ácido ascórbico & $50 \mu \mathrm{g} \mathrm{mL}^{-1}$ & Bovina & FOPAs & 12 & Sim & NA & NA & Thomas et al. (2001) \\
\hline Ácido protocatecuico & $56,25 \mathrm{~g} / \mathrm{mL}$ & Ovina & FOPAs & 12 & Não & Sim & Não & Menezes et al. (2017) \\
\hline Eugenol & $5,0 \mu \mathrm{M}$ & Bovina & FOPAs & 18 & Não & Sim & $\operatorname{Sim}$ & Vasconcelos et al. (2021) \\
\hline Kaempferol & $1 \mu \mathrm{M}$ & Ovina & FOPAs & 12 & Sim & Sim & Não & Santos et al. (2019) \\
\hline \multirow{2}{*}{ Leptina } & $25 \mathrm{ng} / \mathrm{mL}$ & \multirow{2}{*}{ Ovina } & FOPAs & 18 & Sim & Sim & $\operatorname{Sim}$ & Macedo et al. (2019) \\
\hline & $2 \mathrm{ng} / \mathrm{mL}$ & & FOAs & 12 & $\begin{array}{l}\text { Folicular - Não } \\
\text { Oocitário - Sim }\end{array}$ & NA & Não & Menezes et al. (2019) \\
\hline \multirow{3}{*}{ Melatonina } & 100 e $1000 \mathrm{pg} / \mathrm{mL}$ & Caprina & FOPAs & 12 & Sim & $\operatorname{Sim}$ & NA & Barros et al. (2013) \\
\hline & $1000 \mathrm{pg} / \mathrm{mL}$ & \multirow{2}{*}{ Ovina } & FOPAs & 18 & Sim & $\operatorname{Sim}$ & Sim & Barros et al. (2020a) \\
\hline & $500 \mathrm{pg} / \mathrm{mL}$ & & FOAs & 12 & Sim & NA & Sim & Barros et al. (2020b) \\
\hline Resveratrol & $2 \mu \mathrm{M}$ & \multirow{2}{*}{ Ovina } & FOPAs & 18 & Sim & Sim & Sim & Macedo et al. (2017) \\
\hline Rutina & $0,1 \mu \mathrm{g} / \mathrm{mL}$ & & FOPAs & 12 & Não & Sim & Sim & Lins et al. (2017) \\
\hline
\end{tabular}

Nota: FOPAs: Folículos ovarianos pré-antrais. FOAs: Folículos ovarianos antrais. NA: Não avaliado. $\uparrow$ : Aumentou. $\downarrow$ : Diminuiu. Fonte: Autores. 
Dentre os inúmeros antioxidantes estudados, a nossa equipe tem obtido significativos avanços com a adição do antioxidante anetol no meio de CIV de FOPAs e FOAs caprinos. O anetol (trans-1-metoxi-4-1-propenil-benzeno) é uma substância fenólica natural, farmacologicamente ativa, encontrada em óleos essenciais de algumas plantas aromáticas, como Croton zehntneri (Polzin, Stanfill, Brown, Ashley, \& Watson, 2007). No cultivo in situ de FOPAs, o anetol aumentou significativamente a sobrevivência, ativação, diâmetro oocitário e folicular, bem como reduziu os níveis de EROs exógenas de modo concentração dependente (Sá et al., 2018). Por outro lado, depois do CIV de FOPAs isolados, o anetol resultou na formação de antro e reduziu significativamente os níveis de EROs exógenas. Já no CIV de FOAs isolados, o anetol manteve a sobrevivência, aumentou o diâmetro oocitário e folicular, a secreção de esteroides, a capacidade antioxidante e diminuiu a expressão de gene pró-apoptótico (BAX), bem como níveis de EROs exógenas no meio coletado após o CIV. Além disso, aumentou significativamente as taxas de maturação $(57,7 \%)$, mórulas e blastocistos $(10,0 \%)$ que resultou em uma prenhez após transferência de embriões clivados (Sá et al., 2017; Sá et al., 2020).

Vale salientar que apesar desses resultados, estudos têm indicado outras alternativas para incrementar a composição dos meios e ao mesmo tempo, reduzir níveis de EROs exógenas e consequentemente regular o PM. Uma das alternativas seria a adição de meio produzido a partir de células previamente cultivadas, como o MC produzido a partir de CTMs (Bezerra et al., 2019). O MC já teve atividade antioxidante comprovada e potencialmente pode regular o PM .

\subsection{Importância das Células-Tronco para o Cultivo In Vitro de Folículos Ovarianos}

\subsubsection{Células-Tronco}

Células-tronco (CT) são células capazes de autorrenovar-se e colonizar o organismo, por meio de mitoses simétricas e assimétricas, com níveis de plasticidade distintos (Amorin et al., 2012). Adicionalmente, as CT apresentam o potencial de se diferenciar em diversos tipos celulares (Blau, Brazelton, \& Weimann, 2001) sob influência de estímulos adequados in vitro, tais como bioquímico, hormonal e mecânico (Csaki, Matis, Mobasheri, \& Shakibaei, 2007).

Vale salientar que as CT podem ser classificadas quanto ao seu potencial de diferenciação em unipotentes ou oligopotentes, totipotentes, pluripotentes e multipotentes. As uni ou oligopotentes são células com certo grau de diferenciação e sua potencialidade é destinada a uma linhagem celular específica, como as CT hematopoiéticas. As células totipotentes estão envolvidas nos dias iniciais do desenvolvimento embrionário e podem se diferenciar em todos os tipos de células e tecidos funcionais do organismo, dentre estes, os anexos embrionários. Já as células pluripotentes são localizadas no estádio embrionário de blastocisto, e também se diferenciam em diversos tipos celulares, exceto em anexos embrionários (Schipani \& Kronenberg, 2009; Faita, Silva, Sattin, Pinheiro, \& Ambrósio, 2016). Dentre as multipotentes, destacam-se as CTMs, que podem ser coletadas a partir de um tecido formado.

\subsubsection{Células-Tronco Mesenquimais}

As CTMs, inicialmente eram reconhecidas por se diferenciarem nos tipos celulares de origem mesodermal, mas recentemente é notório seu potencial em se diferenciar nas linhagens celulares de outros folhetos embrionários, além de apresentarem a capacidade de retornarem a ser pluripotentes após indução. Diante disso, para assegurar que populações heterogêneas de CTMs não fossem confundidas por outros tipos celulares, a Sociedade Internacional de Terapia Celular determinou três critérios para definir as CTMs e estes incluem: 1) a capacidade de aderir ao plástico perante as condições ideais de cultivo; 2) devem expressar (CD73, CD90 e CD105 +) ou não (CD14, CD34 e CD45 -) grupamentos de diferenciação e por fim 3) possuir potencial de se diferenciar em osteo e condroblastos, e adipócitos (Dominici et al., 2006; Bydlowski, Debes, Maselli, \& Janz, 2009). 
As CTMs têm ganhado destaque na medicina regenerativa por substituir células ou tecidos lesados (Martins et al., 2014) e secretar substâncias que podem interagir com células no CIV, por meio de sinalização parácrina (Takahashi et al., 2007; Tyndall \& Pistoia, 2009). Vale salientar que as CTMs podem ser coletadas a partir de diversas fontes, como medula óssea (MO; Neves et al., 2020); tecido adiposo (TA; Green, Zhou, \& Shikanov, 2016); sangue do cordão umbilical (SCU; Elfayomy, Almasry, El-Tarhouny, \& Eldomiaty, 2016) e geleia de Wharton (GW; Sousa et al., 2021). A coleta das CTMsGW tem ganhado grande evidência devido a ausência de conflitos éticos envolvidos em sua coleta e aplicação, por exemplo, quando comparado aos métodos invasivos relacionados na obtenção de CTMs advindas da MO (Asgari et al., 2015) e TA (Green, Zhou, \& Shikanov, 2016).

A GW é uma uma matriz mucosa localizada no cordão umbilical, rica em proteoglicanos e uma fonte fundamental de CTMs (La Rocca, 2011). As CTMs obtidas desse local já foram estudadas em diversas espécies: humana (Bongso \& Fong, 2013), bubalina (Bhardwaj, Ansari, Parmar, Vikash, \& Sharma, 2016), ovina (Bezerra et al., 2019) e caprina (Azari et al., 2011; Sousa et al., 2021), dentre outras. Portanto, esses estudos foram realizados com as CTMs-GW devido a sua produção e liberação de substâncias ao meio em que são cultivadas. Essa substâncias são imprescindíveis para o desenvolvimento tanto oócitário quanto folicular (Asgari et al., 2015).

\subsubsection{Substâncias Secretadas por Células-Tronco Mesenquimais e Benefícios para o Cultivo In Vitro}

As CTMs secretam uma série de substâncias, como: citocinas; fatores de crescimento (MCP-1, VEGF-A, EGF, FGF-2, LIF e TGF- $\beta$ - Bhardwaj et al., 2016); fatores anti-apoptóticos (BCL-XL, BCL-2 e P32 - Asgharzadeh et al., 2015) e antioxidantes (PRDX5 - Lee et al., 2015).

O co-cultivo de FOPAs isolados (folículos secundários) bubalinos juntamente com CTMs do epitélio germinativo do ovário, estimulou o crescimento folicular e proporcionou a PIVE, com taxas de embriões em torno de 12,2\% (Gupta et al., 2008).

Green et al. (2016) realizaram um estudo com (matriz de hidrogel de alginato + CTMs-TA) para cultivar folículos primários e secundários iniciais isolados de murinos por 14 dias. Tal sistema proporcionou uma maior sobrevivência folicular, crescimento e formação de antro, em comparação com o controle (folículos encapsulados apenas no alginato, sem a utilização de CTMs-TA). Ademais, apenas o grupo cultivado com as CTMs resultou 64\% dos oócitos em MII.

Neves et al. (2020) co-cultivaram FOPAs in situ com CTMs-MO caprina por 7 dias e, foi observado que as CTMs não influenciaram no desenvolvimento folicular e oocitário, bem como nas concentrações de nitrito e GSH. No entanto, foi fundamental para manter a sobrevivência de FOPAs durante os 7 dias de CIV. Já em um estudo recente da nossa equipe (Sousa et al., 2021) foi visto que o co-cultivo de FOPAs in situ com CTMs-GW caprina, melhorou a taxa de ativação e manteve a sobrevivência folicular, exercendo influência positiva na proliferação de CG após 7 dias de CIV.

Portanto, a variação dos resultados provavelmente se deve às diferenças dos sítios em que as CTMs são coletadas; as espécies envolvidas e períodos de CIV. Além disso, dentre os desafios do co-cultivo destaca-se a competição gerada entre as CTMs e folículos, que podem consequentemente gerar EO (Sousa et al., 2021). Por esse motivo, diversos pesquisadores vêm utilizando os meios em que as CTMs são cultivadas, isto é, o MC, que é rico em substâncias secretadas por essas células.

Durante a PIVE em bubalinos, a substituição do meio de CIV por $50 \%$ ou $100 \%$ de MC obtido de CTMs-GW, melhorou significativamente a taxa de formação de blastocistos e qualidade embrionária, comprovada pelo aumento do número de células totais nos blastocistos (Bhardwaj et al., 2016).

No CIV folicular, Bezerra et al. (2019) cultivaram FOPAs ovinos isolados durante 6 dias em 1) $100 \%$ de $\alpha$-MEM ${ }^{+}$ suplementado (controle); 2) $50 \%$ de $\alpha-\mathrm{MEM}^{+}+50 \%$ de MC ou 3) $100 \%$ de MC obtido de CTMs-GW. Após o período de CIV foi observado que os FOPAs cultivados com 50 ou 100\% de MC ( $\alpha$-MEM+MC e MC) tiveram diâmetros e taxas de 
crescimento superiores, bem como níveis inferiores de EROs intracelulares nos oócitos obtidos após o CIV de FOPAs nessas condições.

\section{Considerações Finais}

Diante do exposto, pode-se presumir que o CIV folicular é uma biotécnica em desenvolvimento com importantes aplicações, mas que ainda apresenta resultados limitados. Essa baixa eficiência se deve principalmente a complexa interação de substâncias que atuam no desenvolvimento, bem como fatores ligados a própria biotécnica, que desencadeiam EO e alterações epigenéticas. Como alternativa, estudos recentes têm testado com sucesso diversas substâncias no meio de CIV, como antioxidantes e o MC de CTMs, as quais tem apresentado resultados promissores na foliculogênese. Dessa maneira, futuros estudos investigando o mecanismo de ação de diferentes agentes antioxidantes, assim como seus impactos no PM e desenvolvimento folicular serão de grande relevância.

\section{Referências}

Abedelahi, A., Salehnia, M., \& Allameh, A. A. (2010). Sodium selenite improves the in vitro follicular development by reducing the reactive oxygen species level and increasing the total antioxidant capacity and glutathione peroxide activity. Human Reproduction, 25, 977-985.

Abir, R., Nitke, S., Ben-Haroush, A., \& Fisch, B. (2006). In vitro maturation of human primordial ovarian follicles: Clinical significance, progress in mammals, and methods for growth evaluation: Review. Histology and Histopathology, 21, 887-898.

Agarwal, A., \& Allamaneni, S. S. R. (2004). Role of free radicals in female reproductive diseases and assisted reproduction. Reproduction Biomedicine Online, 9, 338-347.

Aguiar, F. L. N., Gastal, G. D. A., Alves, K. A., Alves, B. G., Figueiredo, J. R., \& Gastal, E. L. (2020). Supportive techniques to investigate in vitro culture and cryopreservation efficiencies of equine ovarian tissue: A review. Theriogenology, 156, 296-309.

Amarowicz, R., Pegg, R. B., Rahimi-Moghaddam, P., Barl, B., \& Weil, J. A. (2004). Free-radical scavenging capacity and antioxidant activity of selected plant species from the Canadian prairies. Food Chemistry, 84(4), 551-562.

Amorin, B., Valim, V. S., Lemos, N. E., Júnior, L. M., Silva, A. M. P., Silva, M. A. L., \& Silla, L. (2012). Células-tronco mesenquimais - caracterização, cultivo, propriedades imunológicas e aplicações clínicas. Revista HCPA, 32, 71-81.

Andrade, E. R., Van Den Hurk, R., Lisboa, L. A., Hertel, M. F., Melo-Sterza, F. A., Moreno, K., Bracarense, A. P., Landim-Alvarenga, F. C., Seneda, M. M., \& Alfieri, A. A. (2012). Effects of ascorbic acid on in vitro culture of bovine preantral follicles. Zygote, 5, 1-10.

Ang, L., Haixia, C., Hongxia, L., Ruijiao, L., Xingping, G., \& Huaixiu, W. (2021). Supplementation of c-type natriuretic peptide during in vitro growth period benefits the development of murine preantral follicles. Zygote, 29(2), 150-154.

Arunakumari, G., Shanmugasundaram, N., \& Rao, V. H. (2010). Development of morulae from the oocytes of cultured sheep preantral follicles. Theriogenology, 74, 884-894.

Asgari, H. R., Akbari, M., Abassi, M., Ai, J., Korouji, M., Aliakbari, F., Babatunde, K. A., Aval, F. S., \& Joghataei, M. T. (2015). Human Wharton's jellyderived mesenchymal stem cells express oocyte developmental genes during co-culture with placental cells. Iranian Journal of Basic Medical Sciences, 18(1), 22-29.

Asgharzadeh, S., Mirshokraei, P., Hassanpour, H., Ahmadi, E., \& Nazari, H. (2015). The effect of mesenchymal stem cells as co-culture in in vitro nuclear maturation of ovine oocytes. Animal Science Papers and Reports, 33, 223-232.

Azari, O., Babaei, O., Derakhshanfar, A., Nematollahi-Mahani, S. N., Poursahebi, R., \& Moshrefi, M. (2011). Effects of transplanted mesenchymal stem cells isolated from Wharton's jelly of caprine umbilical cord on cutaneous wound healing, histopathological evaluation. Veterinary Research Communications, 35, 211-222.

Baumann, C., Olson, M., Wang, K., Fazleabas, A., De La Fuente, R. (2015). Arginine methyltransferases mediate an epigenetic ovarian response to endometriosis. Reproduction, 150(4), 297-310.

Barros, V. R., Cavalcante, A. Y. P., Macedo, T. J. S, Barberino, R. S., Lins, T. L. B., Menezes, V. G., Queiroz, M. A. A., Araújo, V. R., Palheta J. R. R. C., Leite, M. C. P., \& Matos, M. H. T. (2013). Immunolocalization of Melatonin and Follicle-Stimulating Hormone Receptors in Caprine Ovaries and their Effects During in vitro Development of Isolated Pre-Antral Follicles. Reproduction in Domestic Animals, 48(6), 1025-1033.

Barros, V. R. P., Monte, A. P. O., Santos, J. M. S., Lins, T. L. B. G., Cavalcante, A. Y. P., Gouveia, B. B., Muller, M. C., Junior, J. L. O., Donfack, N. J., Araújo, V. R., \& Matos, M. H. T. (2020a). Melatonin improves development, mitochondrial function and promotes the meiotic resumption of sheep oocytes from in vitro grown secondary follicles. Theriogenology, 144, 67-73. 
Barros, V. R. P., Monte, A. P. O., Santos, J. M. S., Lins, T. L. B. G., Cavalcante, A. Y. P., Gouveia, B. B., Muller, M. C., Junior, J. L. O., Barberino, R. S., Donfack, N. J., Araújo, V. R., \& Matos, M. H. T. (2020b). Effects of melatonin on the in vitro growth of early antral follicles and maturation of ovine oocytes. Domestic Animal Endocrinology, 71, 106386.

Bennemann, J., Grothmann, H., \& Wrenzycki, C. (2018). Reduced oxygen concentration during in vitro oocyte maturation alters global DNA methylation in the maternal pronucleus of subsequent zygotes in cattle. Molecular Reproduction and Development, 85(11), 849-857.

Bezerra, M. E. S., Monte, A. P. O., Barberino, R. S., Lins, T. L. B. G., Junior, J. L. O., Santos, J. M. S., Bezerra, D. O., Neves, C. A., Silva, G. S., Carvalho, M. A. M., \& Matos, M. H. T. (2019). Conditioned medium of ovine Wharton's jelly-derived mesenchymal stem cells improves growth and reduces ROS generation of isolated secondary follicles after short-term in vitro culture. Theriogenology, 125, 56-63.

Bhardwaj, R., Ansari, M. M., Parmar, M. S., Vikash, C., \& Sharma, G. T. (2016). Stem Cell Conditioned Media Contains Important Growth Factors and Improves In vitro Buffalo Embryo Production. Animal Biotechnology, 27, 118-125.

Blau, H. M., Brazelton, T. R., \& Weimann, J. M. (2001). The evolving concept of a stem cell: entity or function? Cell, 105(7), 829-841.

Bomfim, M. M., Andrade, G. M., Collado, M. D., Sangalli, J. R., Fontes, P. K., Nogueira, M. F. G., Meirelles, F. V., Silveira, J. C., \& Perecin, F. (2017). Antioxidant responses and deregulation of epigenetic writers and erasers link oxidative stress and DNA methylation in bovine blastocysts. Molecular Reproduction and Development, 84(12), 1296-1305.

Bongso, A., \& Fong, C.Y. (2013). The therapeutic potential, challenges and future clinical directions of stem cells from the Wharton's jelly of the human umbilical cord. Stem Cell Reviews and Reports, 9(2), 226-240.

Brasileiro, A. M M. (2013) Manual de produção de textos acadêmicos e científicos. São Paulo: Atlas. 47 páginas.

Bunkar, N., Pathak, N., Lohiya, N. K., \& Mishra, P. K. (2016). Epigenetics: A key paradigm in reproductive health. Clinical and Experimental Reproductive Medicine, 43(2), 59.

Bydlowski, S. P., Debes, A. A., Maselli, L. M. F., \& Janz, F. L. (2009) Características biológicas das células-tronco mesenquimais. Revista Brasileira de Hematologia e Hemoterapia, 31(1), 25-35.

Cadenas, J., Leiva-Revilla, J., Vieira, L. A., Apolloni, L. B., Aguiar, F. L. N., Alves, B. G., Lobo, C. H., Rodrigues, A. P. R., Apgar, G. A., Smitz, J., Figueiredo, J. R., \& Maside, C. (2017). Caprine ovarian follicle requirements differ between preantral and early antral stages after IVC in medium supplemented with GH and VEGF alone or in combination. Theriogenology, 87, 321-332.

Cadenas, J., Maside, C., Ferreira, A. C. A., Vieira, L. A., Leiva-Revilla, J., Paes, V., Alves, B. G., Brandão, F. Z., Rodrigues, A. P. R., Wheeler, M. B., \& Figueiredo, J. R. (2018). Relationship between follicular dynamics and oocyte maturation during in vitro culture as a non-invasive sign of caprine oocyte meiotic competence. Theriogenology, 107, 95-103.

Cavalcante, A.Y. P., Gouveia, B. B., Barberino, R. S., Lins, T. L., Santos, L. P., Gonçalves, R. J., Celestino, J. J., \& Matos, M. H. (2015). Kit ligand promotes the transition from primordial to primary follicles after in vitro culture of ovine ovarian tissue. Zygote, 24, 578-582.

Cavalcante, B. N., Matos-Brito, B. G., Paulino, L. R., Silva, B. R., Aguiar, A. W. M., Almeida, E. F. M., Souza, A. L. P., Vasconcelos, G. L., Ernando, I. T. A., Silva, A. W. B., \& Silva, J. R. B. (2019). Effects of melatonin on morphology and development of primordial follicles during in vitro culture of bovine ovarian tissue. Reproduction in Domestic Animals, 54(12), 1567-1573.

Chen, Z., LI, S., Subramaniam, S., Shyy, J. Y. J., \& Chien, S. (2017). Epigenetic regulation: a new frontier for biomedical engineers. Annual Review of Biomedical Engineering, 19, 195-219.

Chelenga, M., Sakaguchi, K., Abdel-Ghani, M. A., Yanagawa, Y., Katagiri, S., \& Nagano, M. (2020). Effect of increased oxygen availability and astaxanthin supplementation on the growth, maturation and developmental competence of bovine oocytes derived from early antral follicles. Theriogenology, 157, 341349 .

Cloos, P. A., Christensen, J., Agger, K., Maiolica, A., Rappsilber, J., Antal, T., Hansen, K. H., \& Helin, K. (2006). Histone demethylation by a family of JmjC domain-containing proteins. Nature, 439(7078), 811-816.

Costa, S. L., Costa, E. P., Pereira, E. C. M., Benjamin, L. A., Rodrigues, M. T., Mendes, V. R. A., \& Silva, T. F. (2014). Influence of Insulin-like Growth Factor I (IGF-I) on the survival and the in vitro development of caprine preantral follicles. Pesquisa Veterinária Brasileira, 34, 1037-1044.

Csaki, C., Matis, U., Mobasheri, A., Ye, H., \& Shakibaei, M. (2007). Chondrogenesis, osteogenesis and adipogenesis of canine mesenchymal stem cells: a biochemical, morphological and ultrastructural study. Histochemistry and Cell Biology, 128, 507-520.

Covarrubias, L., Hernández-García, D., Schnabel, D., Salas-Vidal, E., \& Castro-Obregón, S. (2008). Function of reactive oxygen species during animal development: passive or active? Developmental Biology, 320(1), 1-11.

Dahl, J. A., Jung, I., Aanes, H., Greggains, G. D., Manaf, A., Lerdrup, M., Li, G., Kuan, S., Li, B., Lee, A. Y., Preissl, S., Jermstad, I., Haugen, M. H., Suganthan, R., Bjoras, M., Hansen, K., Dalen, K. T., Fedorcsak, P., Bing, R., \& Klungland, A. (2016). Broad histone H3K4me3 domains in mouse oocytes modulate maternal-to-zygotic transition. Nature, 537(7621), 548-552.

Devine, P. J., Pereeault, S. D., \& Luderer, U. (2012). Roles of reactive oxygen species and antioxidants in ovarian toxicity. Biology Reproduction, 86(2), 1-10.

Dominici, M., Le Blanc, K., Mueller, I., Slaper-Cortenbach, I., Marini, F. C., Krause, D. S., Deans, R. J., Keating, A., Prockop, D. J., \& Horwitz, E. M. (2006). Minimal criteria for defining multipotent mesenchymal stromal cells. The International Society for Cellular Therapy position statement. Cytotherapy, $8(4)$, 315-317.

Du Plessis, S. S., Makker, K., Desai, N. R., \& Agarwal, A. (2008). Impact of oxidative stress on IVF. Expert Review of Obstetrics \& Gynecology, 3, 539-554. 
Durlej, M. G., Duda, M., Knapcyk, K., \& Słomczyńska, M. (2008). Effects of transferrin on aromatase activity in porcine granulosa cells in vitro. Folia Histochemica Et Cytobiologica, 46, 423-428.

Edson, M. A., Nagaraja, A. K., \& Matzuk, M. M. (2009). The mammalian ovary from genesis to revelation. Endocrine Reviews, 30(6), 624-712.

Elfayomy, A. K., Almasry, S. M., El-Tarhouny, S. A., \& Eldomiaty, M. A. (2016). Human umbilical cord blood-mesenchymal stem cells transplantation renovates the ovarian surface epithelium in a rat model of premature ovarian failure: Possible direct and indirect effects. Tissue and Cell, $48,370-382$.

Eppig, J. J., \& Downs, S. M. (1987). The effect of hypoxanthine on mouse oocyte growth and development in vitro: maintenance of meiotic arrest and gonadotropin-induced oocyte maturation. Developmental Biology, 199, 313-321.

Eppig, J. J., \& O'brien, M. J. (1996). Development in vitro of mouse oocytes from primordial follicles. Biology of Reproduction, $54,197-207$.

Faita, T., Silva, V. N., Sattin, W. R., Pinheiro, A. O., \& Ambrósio, C. E. (2016). Membrana amniótica: fonte alternativa de células-tronco mesenquimais em diversas espécies animais. Pesquisa Veterinária Brasileira, 36(6), 520-525.

Fang, Z., Yang, S., \& Wu, G. (2002). Radicais livres, antioxidantes e nutrição. Nutrição, 18, 872- 879.

Ferreira, A. C. A., Maside, C., Sá, N. A. R., Guerreiro, D. D., Correia, H. H. V., Leiva-Revilla, J., Lobo, C. H., Araújo, V. R., Apgar, G. A., Brandão, F. Z., Figueiredo, J. R., \& Campello, C. C. (2016). Balance of insulin and FSH concentrations improves the in vitro development of isolated goat preantral follicles in medium containing GH. Animal Reproduction Science, 165, 1-10.

Ferreira, A. C. A., Sá, N. A., Cadenas, J., Correia, H. H., Guerreiro, D. D., Alves, B. G., Lima, L. F., Celestino, J. J. H., Rodrigues, A. P. R., Gastal, E. L., \& Figueiredo, J. R. (2020). Pituitary porcine FSH, and recombinant bovine and human FSH differentially affect growth and relative abundances of mRNA transcripts of preantral and early developing antral follicles in goats. Animal Reproduction Science, 219,106461

Figueiredo, J. R., Hulshof, S. C., Van Den Hurk, R., Nusgens, B., Bevers, M. M., Ectors, F. J., \& Beckers, J. F. (1994). Preservation of oocyte and granulosa cell morphology in bovine preantral follicles cultured in vitro. Theriogenology, 41, 1333-1346.

Figueiredo, J. R., Rodrigues, A. P. R., Amorim, C. A., \& Silva, J. R. V. Manipulação de oócitos inclusos em folículos ovarianos pré-natais, In: Gonçalves PBD, Figueiredo JR, Freitas VJF (Editors). (2008). Biotécnicas Aplicadas a Reprodução animal. São Paulo: Roca, 261-291.

Figueiredo, J. R., \& Lima, L. F. (2017). Tecnologia do ovário artificial: aplicações, estado da arte, limitações e perspectivas. Revista Brasileira de Reprodução Animal, 41(1), 248-253.

Figueiredo, J. R., Cadenas, J., Lima, L. F., \& Santos, R. R. (2019). Advances in in vitro folliculogenesis in domestic ruminants. Animal Reproduction (AR), $16(1), 52-65$

Fortune, J. E., Rivera, G. M., Evans, A. C. O., \& Turzillo, A. M. (2001). Differentiation of dominant versus subordinate follicles in cattle. Biology Reproduction, 65, 648-645.

Fujii, J., Iuchi, Y., \& Okada, F. (2005). Fundamental roles of reactive oxygen species and protective mechanisms in the female reproductive system. Reproduction Biology Endocrinology, 3, 43

Glanzner, W. G., Wachter, A., Coutinho, A. R. S., Albornoz, M. S., Duggavathi, R., Gonçalves, P. B., \& Bordignon, V. (2017). Altered expression of BRG1 and histone demethylases, and aberrant H3K4 methylation in less developmentally competent embryos at the time of embryonic genome activation. Molecular Reproduction and Development, 84(1), 19-29.

Glanzner, W. G., Rissi, V. B., Macedo, M. P., Mujica, L. K. S., Gutierrez, K., Bridi, A., Souza, J. R. M., Gonçalves, P. B. D., \& Bordignon, V. (2018). Histone 3 lysine 4, 9, and 27 demethylases expression profile in fertilized and cloned bovine and porcine embryos. Biology of Reproduction, $98(6)$, 742-751.

Green, L. J., Zhou, H., \& Shikanov, A. (2016). Utilization of adipose derived stem cells for the in vitro maturation of primary and early secondary ovarian follicles. Fertility and Sterility, 106, e49.

Gupta, P. S. P., Ramesh, H. S., Manjunatha, B. M., Nandi, S., \& Ravindra, J. P. (2008). Production of buffalo embryos using oocytes from in vitro grown preantral follicles. Zygote, 16, 57-63.

Hammadeh, N., Coomarasamy, A., Ola, B., Papaioannou, S., Afnan, M., \& Sharif, K. (2008). Ultrasound-guided hydrosalpinx aspiration during oocyte collection improves outcome in IVF: a randomized controlled trial. Human Reproduction, 23, 1113- 1117.

Hiyun, K., Jeon, J., Park, K., \& Kim, J. (2017). Writing, erasing and reading histone lysine methylations. Experimental \& Molecular Medicine, 49, 324.

Huang, W., Nagano, M., Kang, S. S., Yanagawa, Y., \& Takahashi, Y. (2013). Effects of in vitro growth culture duration and prematuration culture on maturational and developmental competences of bovine oocytes derived from early antral follicles. Theriogenology, 80(7), 793-799.

Huang, J., Zhang, H., Wang, X., Dobbs, K. B., Yao, J., Qin, G., Whitworth, K., Walters, E. M., Prather, R. S., \& Zhao, J. (2015). Impairment of preimplantation porcine embryo development by histone demethylase KDM5B knockdown through disturbance of bivalent H3K4me3-H3K27me3 modifications. Biology of Reproduction, 92(3).

Idelchik, M. D. P. S., Begley, U., Begley, T. J., \& Melendez, J. A. (2017). Seminars in Cancer Biology. Academic Press, 57-66.

Itoh, T., Kacchi, M., Abe, H., Sendai, Y., \& Hoshi, H. (2002). Growth, Antrum Formation, and Estradiol Production of Bovine Preantral Follicles Cultured in a Serum-Free Medium. Biology of Reproduction, 67, 1099-1105.

Juengel, J. L., Sawyer, H. R., Smith, P. R., Quirke, L. D., Heath, D. A., Lun, S., Wakefield, S. J., Mcnatty, K. P. (2002). Origins of follicular cells and ontogeny of steroidogenesis in ovine fetal ovaries. Molecular and Cellular Endocrinology, 191, 1-10. 
Kaipia, A., \& Hsueh, A. J. (1997). Regulation of ovarian follicle atresia. Annual Review of Physiology, 59(1), 349-363.

Klose, R. J., Yamane, K., Bae, Y., Zhang, D., Erdjument-Bromage, H., Tempst, P., Wong, J., \& Zhang, Y. (2006). The transcriptional repressor JHDM3A demethylates trimethyl histone H3 lysine 9 and lysine 36. Nature, 442(7100), 312-316.

Laguerre, M., Lecomte, J., \& Villeneuve, P. (2007). Evaluation of the ability of antioxidants to counteract lipid oxidation: Existing methods, new trends and challenges. Progress in Lipid Research, 46(5), p. 244-282.

La Rocca, G. (2011). Connecting the dots: The promises of wharton's jelly stem cells for tissue repairand regeneration. The Open Tissue Engineering and Regenerative Medicine Journal, 4, 3-5.

Lee, S. E., Moon, J. J. M., Kim, E. Y., \& Park, S. P. (2015). Stem cell-derived bioactive materials accelerate development of porcine in vitro-fertilized embryos. Cellular Reprogramming (Formerly" Cloning and Stem Cells"), 17(3), 181-190.

Leitão, C. C. F., Costa, J. J. N., Brito, I. R., Magalhães-Padilha, D. M., Almeida, A. P., Figueiredo, J. R., Van Den Huk, R., \& Silva, J. R. V. (2014). Effects of GDF-9 and FSH on mRNA expression for FSH-R, GDF-9 and BMPs in in vitro cultured goat preantral follicles. Brazilian Archives of Biology and Technology, 57(2), 200-208.

Lima-Verde, I. B., Matos, M. H. T., Bruno, J. B., Martins, F. S., Santos, R. R., Báo, S. N., Luque, M. C. A., Vieira, G. A. B., Silveira, E. R., Rodrigues, A. P. R., Figueiredo, J. R., Oliveira, M. A. L., \& Lima, P. F. (2009). Effects of $\alpha$-tocopherol and ternatin antioxidants on morphology and activation of goat preantral follicles in vitro cultured. Arquivo Brasileiro de Medicina Veterinária e Zootecnia, 61(1), 57-65.

Lins, T. L. B. G., Cavalcante, A. Y. P., Santos, J. M. S., Menezes, V. G., Barros, V. R. P., Barberino, R. S., Bezerra, M. E. S., Macedo, T. J. S., \& Matos, M. H. T. (2017). Rutin can replace the use of three other antioxidants in the culture medium, maintaining the viability of sheep isolated secondary follicles. Theriogenology, 89, 263-270.

Liu, W., Liu, X., Wang, C., Gao, Y., Gao, R., Kou, X., Zhao, Y., Li, J., Wu, Y., Xiu, W., Wang, S., Yin, J., Liu, W., Cai, T., Wang, H., Zhang, Y., \& Gao, S. (2016). Identification of key factors conquering developmental arrest of somatic cell cloned embryos by combining embryo biopsy and single-cell sequencing. Cell Discovery, 2(1), 1-15.

Liu, J., Zhang, W., Wu, Z., Dai, L., \& Koji, T. (2018). Changes in DNA methylation of oocytes and granulosa cells assessed by HELMET during folliculogenesis in mouse ovary. Acta Histochemica et Cytochemica, 17039.

Liu, Z., Zhang, G., Deng, M., Yang, H., Pang, J., Cai, Y., Wan, Y., Wang, F. (2020). Inhibition of lysine-specific histone demethylase 1A results in meiotic aberration during oocyte maturation in vitro goats. Theriogenology, 143, 168-178.

Macedo, T. J. S., Barros, V. R. P., Monte, A. P. O., Gouveia, B. B., \& Bezerra, M. É. S. (2017). Resveratrol has dose-dependent effects on DNA fragmentation and mitochondrial activity of ovine secondary follicles cultured in vitro. Zygote, 25(4), 434.

Macedo, T. J. S., Santos, J. M. S., Bezerra, M. É. S., Menezes, V. G., Gouveia, B. B., Barbosa, L. M. R., Lins, T. L. B. G., Monte, A. P. O., Barberino, R. S., Bastista, A. M., Barros, V. R. P., Wischral, A., Queiroz, M. A. A., Araújo, G. G. L., \& Matos, M. H. T. (2019). Immunolocalization of leptin and its receptor in the sheep ovary and in vitro effect of leptin on follicular development and oocyte maturation. Molecular and Cellular Endocrinology, $495,110506$.

Magalhães, D. M., Duarte, A. B. G., Araújo, V. R., Brito, I. R., Soares, T. G., Lima, I. M. T., Lopes, C. A. P., Campello, C. C., Rodrigues, A. P. R., \& Figueiredo, J. R. (2011). In vitro production of a caprine embryo from a preantral follicle cultured in media supplemented with growth hormone. Theriogenology, 75, 182-188.

Magalhães-Padilha, D. M., Geisler-Lee, J., Wischral, A., Gastal, M. O., Fonseca, G. R., Eloy, Y. R. G., Geisler, M., Figueiredo, J. R., \& Gastal, E. L. (2013). Gene expression during early folliculogenesis in goats using microarray analysis. Biology of Reproduction, 89, 1-12.

Manabe, N., Goto, Y., Matsuda-Minehata, F., Inoue, N., Maeda, A., Sakamaki, K., \& Miyano, T. (2004). Regulation mechanism of selective atresia in porcine follicles: regulation of granulosa cell apoptosis during atresia. Journal of Reproduction and Development, 50(5), $493-514$.

Matsuda, F., Inoue, N., Goto, Y., Maeda, A., Cheng, Y., Sakamaki, K., \& Manabe, N. (2008). cFLIP regulates death receptor-mediated apoptosis in an ovarian granulosa cell line by inhibiting procaspase-8 cleavage. Journal of Reproduction and Development, 54(5), 314-320.

Martins, G. R., Teixeira, M. F. S., Junior, R. Q. B., Dias, R. P., Aguiar, T. D. F., Marinho, R. C., \& Pinheiro, A. R. A. (2014). Células-tronco mesenquimais: características, cultivo e uso na Medicina Veterinária. Revista Brasileira de Higiene e Sanidade Animal, 8, $181-202$.

Mcgee, E. A., \& Hsueh, A. J. (2000). Initial and cyclic recruitment of ovarian follicles. Endocrine Reviews, 21(2), $200-214$.

Mclaughlin, E. A., \& Mciver, S. C. (2009). Awakening the oocyte: controlling primordial follicle development. Reproduction, 137, 1-11.

Mclaughlin, M., \& Telfer, E. E. (2010). Oocyte development in bovine primordial follicles is promoted by activin and FSH within a two-step serum-free culture system. Reproduction, 139, 971-978.

Mcnatty, K. P., Fidler, A. E., Juengel, J. L., Quirke, L. D., Smith, P. R., Heath, D. A., Lundy, T., O'connell, A., \& Tisdall, D. J. (2000). Growth and paracrine factors regulating folicular formation and cellular function. Molecular and Cellular Endocrinology, 163, 11-20.

Metere, A., \& Graves, C. E. (2020). Factors Influencing Epigenetic Mechanisms: Is There A Role for Bariatric Surgery? High-Throughput, 9(1), 6.

Menezes, V. G. (2017). Efeito do ácido protocatecuico sobre o desenvolvimento in vitro de folículos secundários ovinos isolados. Dissertação (Mestrado em Ciência Animal). Universidade Federal do Vale do São Francisco, Campus de Ciências Agrárias, Petrolina - PE, 81f.

Menezes, V. G., Monte, A. P. O., Gouveia, B. B., Lins, T. L. B. G., Donfack, N. J., Macedo, T. J. S., Barberino, R. S., Santos, J. M., Matos, M. H. T., \& Batista, A. M., Wischral, A. (2019). Effects of leptin on the follicular development and mitochondrial activity of ovine isolated early antral follicles cultured in vitro. Theriogenology, 138, 77-83. 
Morais, M. L. G. S. (2018). Efeitos da suplementação de anetol ou robinina na vitrificação e incubação in vitro do tecido ovariano ovino. Dissertação (Mestrado em Ciências Morfofuncionais) - Faculdade de Medicina, Universidade Federal do Ceará, Fortaleza, $69 \mathrm{f}$.

Morohaku, K., Tanimoto, R., Sasaki, K., Kawahara-Miki, R., Kono, T., Hayashi, K., Hirao, Y., \& Obata, Y. (2016). Complete in vitro generation of fertile oocytes from mouse primordial germ cells. Proccedings of the National Academy of Sciences of the United States, 113, 9021-9026.

Nacev, B. A., Feng, L., Lemiesz, A. E., Gao, J., Soshnev, A. A., Kundra, R., Schultz, N., Muir, T. W., \& Allis, C. D. (2019). The expanding landscape of 'oncohistone'mutations in human cancers. Nature, 567(7749), 473-478.

Neves, C. A., Silva, L. S., Carvalho, C. E. S., Carvalho, M. S., Sarmento, J. L. R., Cavalcante, T. V., Arrivabene, M., Neves, T. A., Bezerra, M. E. S., Júnior, A. L. G., Silva, C. M. G., \& Carvalho, A. C. M. (2020). Culture of goat preantral follicles in situ associated with mesenchymal stem cell from bone marrow. Zygote, 28(1), 65-71.

O'brien, M. J., Pendola, J. K., \& Eppig, J. J. (2003). A revised protocol for in vitro development of mouse oocytes from primordial follicles dramatically improves their developmental competence. Biology of Reproduction, 68, 1682-1686.

Okediran, B. S., Biobaku, K. T., Olaifa, F. H., \& Atata, A. J. (2017). Haematological and antioxidant enzyme response to Lead toxicity in male Wistar rats. Ceylon Journal of Science, 46(2), 31-37.

Oktem, O., \& Oktay, K. (2008). The ovary: anatomy and function throughout human life. Annals of the New York Academy of Sciences, 1127(1), 1-9.

Paes, V. M., Lima, L. F., Ferreira, A. C. A., Lobo, C. H., Alves, B. G., Rodrigues, A. P. R., Oliveira, A. C., Figueiredo, J. R., \& Feugang, J. M. (2020). The subtle balance of insulin and thyroxine on survival and development of in vitro cultured caprine preantral follicles enclosed in ovarian tissue. Theriogenology, 147, $10-17$

Panta, A. M. T., Silva, A. F. B., Padilha, R. T., Correia, H. H. V., Rondina, D., Figueiredo, J. R., \& Magalhães-Padilha, D. D. M. (2019). Evaluation of in vitro culture systems for goat preantral follicles using reused ovaries from reproductive biotechniques: An alternative to maximize the potential of reproduction. Reproduction in Domestic Animals, 54(3), 480-485.

Park, K. S., Kim, Y. S., Kim, J. H., Choi, B., Kim, S. H., Tan, A. H., Lee, M. S., Lee, M. K., Kwon, C. H., Joh, J. W., Kim, S. J., \& Kim, K.W. (2010) Trophic molecules derived from human mesenchymal stem cells enhance survival, function, and angiogenesis of isolated islets after transplantation. Transplantation, $15,509-517$.

Pasini, D., Hansen, K. H., Christensen, J., Agger, K., Cloos, P. A., \& Helin, K. (2008). Coordinated regulation of transcriptional repression by the RBP2 H3K4 demethylase and Polycomb-Repressive Complex 2. Genes \& Development, 22(10), 1345-1355.

Pflum, M. K., Tong, J. K., Lane, W. S., \& Schreiber, S. L. (2001). Histone deacetylase 1 phosphorylation promotes enzymatic activity and complex formation. Journal of Biological Chemistry, 276(50), 47733-47741.

Picton, H. M., Harris, S. E., Muruvi, W., \& Chambers, E. L. (2008). The in vitro growth and maturation of follicles. Reproduction, 136(6), 703-715.

Polzin, G. M., Stanfill, S. B., Brown, C. R., Ashley, D. L., \& Watson, C. H. (2007). Determination of eugenol, anethole, and coumarin in the mainstream cigarette smoke of Indonesian clove cigarettes. Food and Chemical Toxicology, 45, 1948-1953.

Qingming, Y., Xianhui, P., Weibao, K., Hong, Y., Yidan, S., Li, Z., Yanan, Z., Yuling, Y., Lan, D., \& Guoan, L. (2010). Antioxidant activities of malt extract from barley (Hordeum vulgare L.) toward various oxidative stress in vitro and in vivo. Food Chemistry, 118, (1), 84-89.

Richards, J. S., \& Pangas, S. A. (2016). The ovary: basic biology and clinical implications. Journal of Clinical Investigation, 120, 963-972.

Rocha, R. M., Lima, L. F., Alves, A. M., Celestino, J. J., Matos, M. H., Lima-Verde, I. B., Bernuci, M. P., Lopes, C. A., Báo, S. N., Campello, C. C., Rodrigues, A. P., \& Figueiredo, J. R. (2013). Interaction between melatonin and follicle-stimulating hormone promotes in vitro development of caprine preantral follicles. Domestic Animal Endocrinology, 44, 1-9.

Rodrigues, P., Limback, D., Mcginnis, L. K., Plancha, C. E., \& Albertini, D. F. (2008). Oogenesis: prospects and challenges for the future. Journal of Cellular Physiology, 216(2), 355-365.

Rodrigues, G. Q., Silva, C. M. G., Faustino, L. R., Bruno, J. B., Magalhães, D. M., Campello, C. C., \& Figueiredo, J. R. (2010). Bovine serum albumin improves in vitro development of caprine preantral follicles. Animal Reproduction, 7, 382-388.

Rossetto, R., Lima-Verde, I. B., Matos, M. H. T., Saraiva, M. V. A., Martins, F. S., Faustino, L. R., Araújo, V. R., Silva, C. M. V., Name, K. P. O., Báo, S. N., Campello, C. C., Figueiredo, J. R., \& Blume, H. (2009). Interaction between ascorbic acid and follicle-stimulating hormone maintains follicular viability after long-term in vitro culture of caprine preantral follicles. Domestic Animal Endocrinology, 37, (2), 112-123.

Sá, N. A. R., Araújo, V. R., Correia, H. H. V., Ferreira, A. C. A., Guerreiro, D. D., Sampaio, A. M., Escobar, E., Santos, F. W., Moura, A. A., Lôbo, C. H., Ceccatto, V. M., Campello, C. C., Rodrigues, A. P. R., Leal-Cardoso, J. H., \& Figueiredo, J. R. (2017). Anethole improves the in vitro development of isolated caprine secondary follicles. Theriogenology, 89, 226-234.

Sá, N. A. R., Bruno, J. B., Guerreiro, D. D., Cadenas, J., Alves, B. G., Cibin, F. W. S., Leal-Cardoso, J. H., Gastal, E. L., \& Figueiredo, J. R. (2018). Anethole reduces oxidative stress and improves in vitro survival and activation of primordial follicles. Brazilian Journal of Medical and Biological Research, 51(8).

Sá, N. A., Ferreira, A. C. A., Sousa, F. G. C., Duarte, A. B. G., Paes, V. M., Cadenas, J., Anjos, J. C., Fernandes, C. C. L., Rosseto, R., Cibin, F. W. S., Alves, B. G., Rodrigues, A. P. R., Rondina, D., Gastal, E. L., \& Figueiredo, J. R. (2020). First pregnancy after in vitro culture of early antral follicles in goats: Positive effects of anethole on follicle development and steroidogenesis. Molecular Reproduction and Development, 87(9), 966-977.

Saeedabadi, S., Abazari-Kia, A. H., Rajabi, H., Parivar, K., \& Salehi, M. (2018). Melatonin improves the developmental competence of goat oocytes. International Journal of Fertility \& Sterility, 12(2), p. 157. 
Sahebkar, A., Serban, M. C., Ursoniu, S., \& Banach, M. (2015). Effect of curcuminoids on oxidative stress: A systematic review and meta-analysis of randomized controlled trials. Journal of Functional Foods, 18, 898-909.

Sales, A. D., Duarte, A. B. G., Rodrigues, G. Q., Lima, L. F., Silva, G. M., Carvalho, A. A., Brito, I. R., Maranguape, R. M. S., Lobo, C. H., Aragão, J. A. S., Moura, A. A., Figueiredo, J. R., \& Rodrigues, A. P. R. (2015). Steady-state level of messenger RNA and immunolocalization of aquaporins 3 , 7 , and 9 during in vitro growth of ovine preantral follicles. Theriogenology, 84(1), 1-10.

Santos, L. P., Barros, V. R., Cavalcante, A. Y., Menezes, V. G., Macedo, T. J., Santos, J. M., Araujo, V. R., Queiroz, M. A., \& Matos, M. H. (2014a). Protein localization of epidermal growth factor in sheep ovaries and improvement of follicle survival and antrum formation in vitro. Reproduction in Domestic Animals, 49, 783-789.

Santos, J. M. S., Menezes, V. G., Barberino, R. S., Macedo, T. J., Lins, T. L., Gouveia, B. B., Barros, V. R., Santos, L. P., Gonçalves, R. J., \& Matos, M. H. (2014b). Immunohistochemical Localization of Fibroblast Growth Factor-2 in the Sheep Ovary and its Effects on Pre-antral Follicle Apoptosis and Development In vitro. Reproduction in Domestic Animals, 49, 522-528.

Santos, J. M. S., Monte, A. P. O., Lins, T. L. B. G., Barberino, R. S., Menezes, V. G., Gouveia, B. B., Macedo, T. J. S., Júnior, J. L. O., Donfack, N. J., \& Matos, M. H. T. (2019). Kaempferol can be used as the single antioxidant in the in vitro culture medium, stimulating sheep secondary follicle development through the phosphatidylinositol 3-kinase signaling pathway. Theriogenology, 136, 86-94.

Schafer, F., \& Buettner, G. R. (2001). Redox environment of the cell as viewed through the redox state of the glutathione disulfide/glutathione couple. Free Radical Biology and Medicine, 11, 1191-1212.

Schipani, E., Kronenberg, H. M. (2009). Adult mesenchymal stem cells. In: Harvard Stem Cell Institute. Stembook, Cambridge, MA: The Stem Cell Research Community, 1-7.

Seneda, M. M., Godmann, M., Murphy, B. D., Kimmins, S., \& Bordignon, V. (2008). Developmental regulation of histone H3 methylation at lysine 4 in the porcine ovary. Reproduction, 135(6), 829-838.

Sha, Q. Q., Jiang, Y., Yu, C., Xiang, Y., Dai, X. X., Jiang, J. C., Ou, X. H., Fan, H. Y. (2020). CFP1-dependent histone H3K4 trimethylation in murine oocytes facilitates ovarian follicle recruitment and ovulation in a cell-nonautonomous manner. Cellular and Molecular Life Sciences, 77(15), 2997-3012.

Silva, G. M., Araujo, V. R., Duarte, A. B. G., Lopes, C. A. P., \& Figueiredo, J. R. (2011a). Papel dos antioxidantes no cultivo in vitro de células ovarianas. Revista Brasiliera de Reprodução Animal, 35(3), 315-326.

Silva, G. M., Araújo, V. R., Duarte, A. B. G., Chaves, R. N., Silva, C. M. G., Lobo, C. H., Almeida, A. P., Matos, M. H. T., Tavares, L. M. T., Campelo, C. C., \& Figueiredo, J.R. (2011b). Ascorbic acid improves the survival and in vitro growth of isolated caprine preantral follicles. Animal Reproduction, 8, 14-24.

Silva, C. T. D., \& Jasiulionis, M. G. (2014). Relação entre estresse oxidativo, alterações epigenéticas e câncer. Ciência e Cultura, 66(1), 38-42.

Souza-Cáceres, M. B., \& Melo-Sterza, F. A. (2017). Metilação de histonas em oócitos de embriões mamíferos. Revista Brasileira de Reprodução Animal, 4(2), $620-627$.

Sousa, R. P., Duarte, A. B. G., Pinto, Y., Sá, N. A. R., Alves, B. G., Cibin, F. W. S., Silva, G. C., Carvalho, C. E. S., Neto, N. M. A., Rodrigues, A. P. R., Silva, C. M. G., Figueiredo, J. R., \& Carvalho, M. A. M. (2021). In vitro activation and development of goat preantral follicles enclosed in ovarian tissue cocultured with mesenchymal stem cells. Reproductive Sciences.

Spitschak, M., \& Hoeflich, A. (2018). Potential functions of IGFBP-2 for ovarian folliculogenesis and steroidogenesis. Frontiers in Endocrinology, 9, 119. Takahashi, K., Tanabe, K., Ohnuki, M., Narita, M., Ichisaka, T., Tomoda, K., \& Yamanaka, S. (2007). Induction of pluripotent stem cells from adult human fibroblasts by defined factors. Cell, 131(5), 861-872.

Telfer, E. E. (1998). In vitro models for oocyte development. Theriogenology, 15(492), 451-60.

Thomas, F. H., Leask, R., Srsen, V., Riley, S. C., Spears, N., \& Telfer, E. E. (2001). Effect of ascorbic acid on health and morphology of bovine preantral follicles during long-term culture. Reproduction-Cambridge, 122(3), 487-495.

Torres-Osorio, V., Urrego, R., Echeverri-Zuluaga, J. J., \& López-Herrera, A. (2019). Oxidative stress and antioxidant use during in vitro mammal embryo production. Review. Revista Mexicana de Ciencias Pecuarias, 10(2), 433-459.

Tsukada, Y. I., Fang, J., Erdjument-Bromage, H., Warren, M. E., Borchers, C. H., Tempst, P., \& Zhang, Y. (2006). Histone demethylation by a family of JmjC domain-containing proteins. Nature, 439(7078), 811-816.

Tyndall, A., \& Pistoia, V. (2009). Mesenchymal stem cells combat sepsis. Nature Medicine, 15(1), 18-20.

Vaanholt, L. M., Milne, A., Zheng, Y., Hambly, C., Mitchell, S. E., Valencak, T. G., Allison, D. B., \& Speakman, J. R. (2016). Oxidative costs of reproduction: Oxidative stress in mice fed standard and low antioxidant diets. Physiology and Behavior, 154, 1-7.

Van Den Hurk, R., \& Zhao, J. (2005). Formation of mammalian oocytes and their growth, differentiation and maturation within ovarian follicles. Theriogenology, 63, 1717-1751.

Vasconcelos, E. M., Costa, F. C., Azevedo, A. V. N., Barroso, P. A. A., Assis, E. I. T., Paulino, L. R. F. M., Silva, B. R., Silva, A. W. B., Souza, A. L. P., \& Silva, J. R. V. (2021). Eugenol influences the expression of messenger RNAs for superoxide dismutase and glutathione peroxidase 1 in bovine secondary follicles cultured in vitro. Zygote, 1-6.

Wrenzycki, C., \& Niemann, H. (2003). Epigenetic reprogramming in early embryonic development: Effects of in-vitro production and somatic nuclear transfer. Reproductive Biomedicine Online, 7, 649-656. 
Research, Society and Development, v. 10, n. 9, e22910918022, 2021

(CC BY 4.0) | ISSN 2525-3409 | DOI: http://dx.doi.org/10.33448/rsd-v10i9.18022

Yamamoto, K., Otoi, T., Koyama, N., Horikita, N., Tachikawa, S., \& Miyano, T. (1999). Development to live young from bovine small oocytes after growth, maturation and fertilization in vitro. Theriogenology, 52(1), 81-89.

Young, I. S., \& Woodside, J. V. (2001). Antioxidants in health and disease. Antioxidants in health and disease. Journal of Clinical Pathology, 54(3), 176-186.

Yu, X. X., Liu, Y. H., Liu, X. M., Wang, P. C., Liu, S., Miao, J. K., Du, Z. Q., \& Yang, C. X. (2018). Ascorbic acid induces global epigenetic reprogramming to promote meiotic maturation and developmental competence of porcine oocytes. Scientific Reports, 8(1), 6132.

Zhou, J., Peng, X., \& Mei, S. (2019). Autophagy in ovarian follicular development and atresia. International Journal of Biological Sciences, $15(4), 726$. 